\title{
Electrophysiological properties of right heart and atrioventricular conducting system in patients with alcoholic cardiomyopathy
}

\author{
CONSTANTIN LUCA \\ From the First Medical Clinic, Department of Cardiology and Coronary Care Unit, \\ Institute of Medicine, Timisoara, Romania
}

SUMMARY In 20 men with alcoholic cardiomyopathy, right atrial and right ventricular monophasic action potential, relative repolarisation rate of phase 3, and effective refractory period were studied, as well as atrioventricular conduction properties. The duration of right atrial monophasic action potential and effective refractory period recorded in the middle of the right atrium was shorter in comparison with control patients while the right atrial relative repolarisation rate phase 3 was unchanged. In 5 patients with atrial fibrillation, after conversion to sinus rhythm, great variations were found between right atrial monophasic action potential duration at 90 per cent and 50 per cent repolarisation, atrial effective refractory period, and right atrial relative repolarisation rate of phase 3 recorded in 3 different sites of the right atrium. The right ventricular monophasic action potential duration at 90 per cent repolarisation was longer, while right ventricular monophasic action potential duration at 50 per cent, and right ventricular relative repolarisation rate of phase 3 were shorter in alcoholics compared with the control group. The greatest differences between right ventricular monophasic action potential duration and ventricular effective refractory period obtained in 3 different sites of the right ventricle was observed in alcoholics with frequent ventricular premature beats.

The alcoholic patients showed PR prolongation in 35 per cent of cases and intraventricular conduction defects in 50 per cent of cases. In 11 patients His bundle electrograms and atrial pacing showed latent conduction disturbances proximal and distal to the bundle of His.

Chronic ethanol ingestion has been found to have deleterious effects on cardiac rhythm and conduction, quite apart from leading to nutritional deficiency (Regan, 1971). Though arrhythmias and conduction disturbances are frequently seen in alcoholics (Evans, 1959; Sereny, 1971), to the best of our knowledge there are only limited electrophysiological data in these patients.

The purpose of this paper is to evaluate the electrophysiological properties of the right heart and the atrioventricular conducting system in patients with alcoholic cardiomyopathy. The patients were investigated with the aid of monophasic action potential recordings, atrial and ventricular pacing, and $\mathrm{His}$ bundle electrograms.

\section{Subjects and methods}

Twenty men aged between 24 and 49 years were studied. All had drunk spirits for more than 10 Received for publication 27 April 1979 years and showed criteria for alcoholic cardiomyopathy (Burch and Giles, 1976). The patients had no clinical features of nutritional heart disease, were on an adequate diet, and had no coronary heart diseases or other primary or secondary heart muscle disease. The laboratory data were noncontributory. None of the patients had been taking cardioactive drugs for at least 4 days before the investigation, nor was premedication given. After informed consent, monophasic action potential recordings were obtained with a bipolar suction electrode catheter passed percutaneously to the right chambers of the heart (Gavrilescu et al., 1972; Puech et al., 1974). His bundle electrograms were recorded using a tripolar electrode, introduced via the right femoral vein (Scherlag et al., 1969). A bipolar electrode was introduced via the brachial or femoral vein into the high right atrium. The atrium was paced up to the rate at which type I (Wenckebach) atrioventricular block occurred. Atrial, ventricular, and atrioventricular nodal refractory 
periods were assessed using the extrastimulus method (Wit et al., 1970) with a basic cycle length of $600 \mathrm{~ms}$ and the extrastimulus of twice diastolic threshold delivered after every 8 th beat. His bundle intervals were measured in sinus rhythm and during atrial pacing. The refractoriness of the right atrium and ventricle was measured during pacing of the heart by the monophasic action potential electrode catheter (Brorson, 1975).

Fifteen subjects aged between 27 and 45 years with non-specific heart or thoracic disorders in whom electrophysiological studies were performed to rule out organic heart disease acted as a control group. The monophasic action potentials were recorded from the mid-right atrium and from the lateral right ventricular wall in all patients. In 3 subgroups of these subjects the monophasic action potentials and investigation of refractoriness were performed from the high, middle, and low right atrium and from the apex, the lateral wall, and the base of the right ventricle:

Group 1 included 5 patients with alcoholic cardiomyopathy who had atrial fibrillation converted to sinus rhythm, and no more than 6 ventricular extrasystoles a minute.

Group 2 consisted of 3 patients with alcoholic cardiomyopathy in stable sinus rhythm with less than 6 ventricular extrasystoles a minute.

Group 3 included 4 of the controls. The monophasic action potentials were analysed according to Brorson (1975) and Cabasson et al. (1975). All calculations were performed from 10 complexes and the measurements were expressed as mean values.

\section{Results}

In the 20 patients with alcoholic cardiomyopathy, 7 demonstrated ST-T segment changes previously regarded as specific (Evans, 1959), and 4 exhibited non-specific ST-T abnormalities. Significant changes in the electrophysiological properties of the atrioventricular conduction system were found. Arrhythmias and conduction disturbances were common in these patients (Table 1). In 3 patients with chronic atrial fibrillation DC shock was successful, but in 2 cases it was not followed by sinus rhythm. In the case with complete atrioventricular block associated with atrial fibrillation and syncopal attacks, the conduction was interrupted proximal to the bundle of His; 2 patients wth normal PR interval had prolonged His-Purkinje conduction times. In 6 patients the HV prolongation was associated with bundle-branch block or fascicular blocks. During atrial pacing at increasing rates, a first group of 7 patients with prolonged PR interval developed the Wenckebach phenomenon proximal to the bundle of
Table 1 Arrhythmias and conduction disturbances found in 20 patients with alcoholic cardiomyopathy

\begin{tabular}{|c|c|c|}
\hline $\begin{array}{l}\text { Chronic atrial fibrillation } \\
\text { Paroxysmal atrial fibrillation } \\
\text { Paroxysmal atrial flutter } \\
\text { Ventricular premature beats > }>/ \mathrm{min} \\
\text { First degree atrioventricular block } \\
\text { Intra-atrial + infra-Hisian } \\
\text { Atrionodal } \\
\text { Atrionodal + infra-Hisian } \\
\text { Infra-Hisian } \\
\text { Complete heart block with atrial fibrillation } \\
\text { Left bundle-branch block } \\
\text { Left anterior hemiblock } \\
\text { Left posterior hemiblock } \\
\text { Right bundle-branch block }\end{array}$ & $\begin{array}{r}6 \\
2 \\
1 \\
10 \\
7\end{array}$ & $\begin{array}{l}1 \\
3 \\
1 \\
2\end{array}$ \\
\hline
\end{tabular}

His at relatively slow rates (between 112 and 138 beats a minute), showing altered intra-atrial or atrionodal conduction. During spontaneous sinus rhythm the $\mathrm{AH}$ interval was within normal limits in 3 cases in this group. A second group of 6 patients with normal PR interval and normal atrionodal conduction time developed a similar Wenckebach phenomenon at a similar pacing rate (between 129 and 135 beats a minute), suggesting latent conduction disturbances in the atrioventricular nodal area. In a third group of 5 patients with normal PR and AH intervals atrial pacing could be increased above 145 beats a minute. The mean effective refractory period of the atrioventricular node in the first group was $387 \mathrm{~ms} \pm 20$, in the second group $353 \mathrm{~ms} \pm 7$, and in the third group $330 \mathrm{~ms} \pm 98$. These values were significantly prolonged compared with a control group (mean $294 \mathrm{~ms} \pm 7$ ).

The following terms were used in order to evaluate the electrophysiological properties of the heart:

(1) The duration of the right atrial and ventricular monophasic action potential complexes measured at 90 per cent and 50 per cent of repolarisation.

(2) The relative repolarisation rate of phase 3 of the right atrial and right ventricular monophasic action potential complexes. This represents the difference in time between 50 per cent and 90 per cent repolarisation (e) expressed as per cent/second using the formula: relative repolarisation rate phase $3=40 \times 1000 / \mathrm{e}$. This index is valuable in assessing phase 3 (Olsson, 1971; Brorson, 1975).

(3) Effective refractory period of the atrium is the longest $S_{1}-S_{2}$ interval at which the premature atrial extrastimulus fails to depolarise the atria.

(4) Effective refractory period of the atrioventricular node is the longest $A_{1}-A_{2}$ interval at which the premature extrastimulus response $\left(\mathbf{A}_{2}\right)$ fails to conduct to the His bundle $\left(\right.$ no $\left.\mathrm{H}_{2}\right)$.

(5) Effective refractory period of the ventricle is the longest $S_{1}-S_{2}$ interval at which the premature 
ventricular extrastimulus fails to depolarise the ventricles.

The schematic illustration of the analyses of a single atrial or ventricular monophasic action potential complex is shown in Fig. 1. Fig. 2 and 3 show examples of the determination of the effective refractory periods in the high, middle, and low right atrium, and in the apex, lateral wall, and base of the right ventricle.

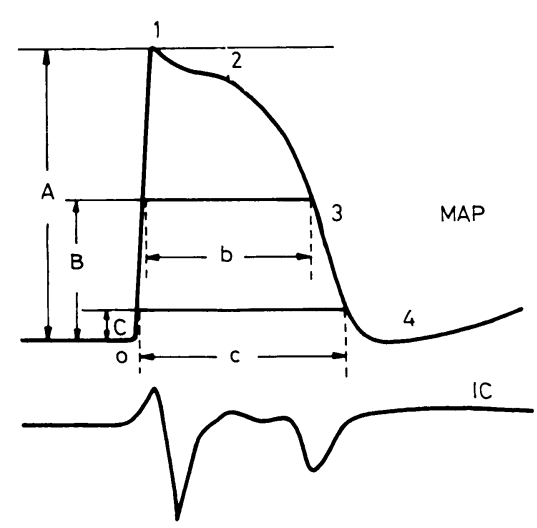

Fig. 1 Schematic illustration of the analyses of a single monophasic action potential complex (MAP). The amplitude of the MAP was measured and expressed in millivolts (A). The duration of the MAP was measured at amplitude of 50 per cent and 90 per cent

repolarisation ( $\mathrm{B}$ and $\mathrm{C}$ ) and expressed in milliseconds $(\mathrm{b}$ and $\mathrm{c}) ; 0,1,2,3$, and 4 represents the phases of MAP complex. IC, intracavitary electrogram.

Comparison of the monophasic action potential complexes recorded from the mid-right atrium between patients with alcoholic cardiomyopathy and the control group showed that the right atrial monophasic action potential duration at 90 per cent and 50 per cent repolarisation and the atrial effective refractory periods were shorter in the patients with cardiomyopathy. No difference was found in the right atrial relative repolarisation rate of phase 3 between these groups (see Table 2). From the right ventricular studies, right ventricular monophasic action potential duration at 50 per cent repolarisation, right ventricular effective refractory period and right ventricular relative repolarisation rate of phase 3 were found to be shorter in the alcoholic cardiomyopathy group. However, right ventricular monophasic action potential duration at 90 per cent repolarisation was longer than in the control group (see Table 2).

Table 3 lists the values of monophasic action potential recordings and effective refractory period determinations obtained from multiple sites from alcoholic patients with atrial and ventricular arrhythmias, as well as from patients with stable sinus rythm and from control subjects. The first group showed the greatest differences in the mean monophasic action potential duration at 90 per cent and 50 per cent repolarisation, right atrial relative repolarisation rate phase $3 \mathrm{per}$ cent/s, and the effective refractory period between the 3 different sites.
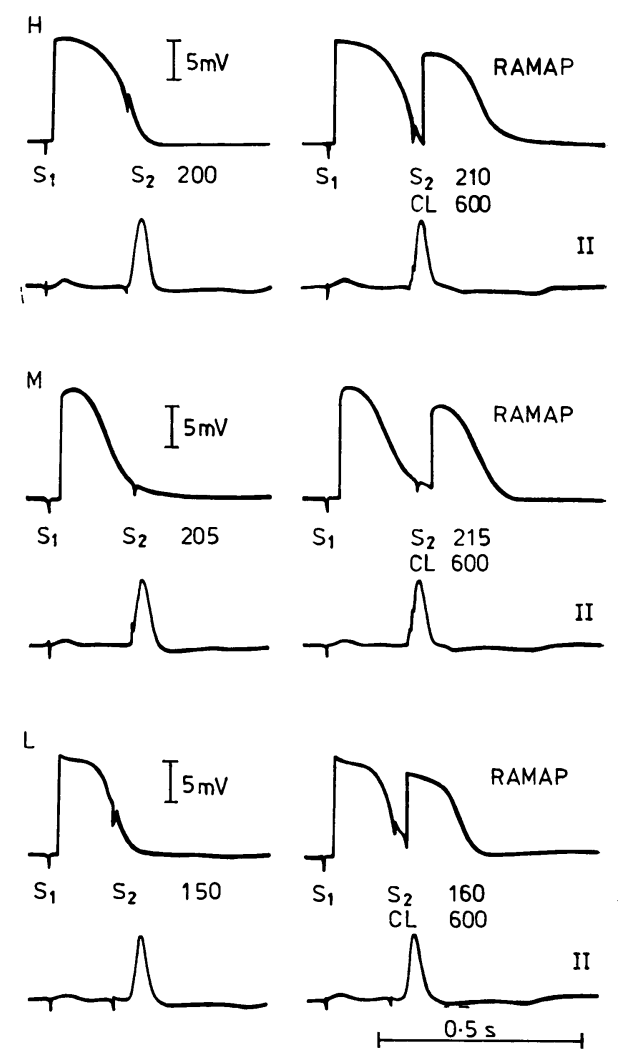

Fig. 2 Case 15. The right atrial monophasic action potential (RAMAP) obtained in the high $(H)$, middle $(M)$, and low $(L)$ right atrium and the determination of the effective refractory period. $S_{1}$, driving stimulus; $S_{2}$ testing stimulus; $C L$, cycle length.

\section{Discussion}

In animals alcohol ingestion produces metabolic disturbances and structural damage as well as depression of myocardial function (Maines and Aldinger, 1967; Opie, 1969; Burch et al., 1971). Alcohol administration in man has been shown to reduce mechanical efficiency of the heart (Mitchell and Cohen, 1970) and to alter the electrocardiogram (Evans, 1959; Gould et al., 1974). Atrial fibrillation, 

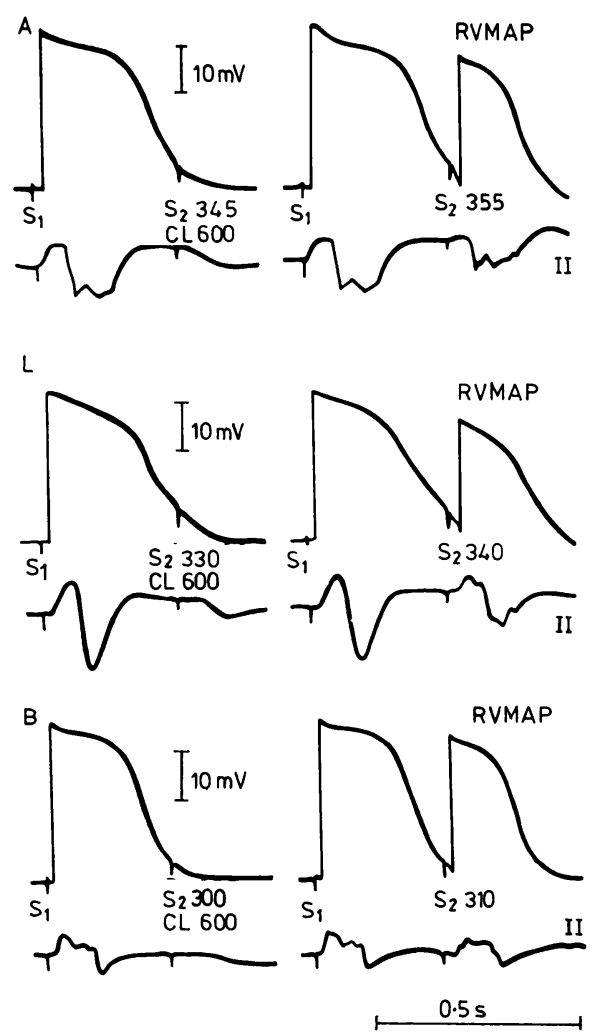

Fig. 3 Case 5. The right ventricular monophasic action potential (RVMAP) obtained in the apex ( $A$ ), lateral wall $(L)$, and base $(B)$ of the right ventricle and the determination of the effective refractory period. $S_{1}$, driving stimulus; $S_{2}$, testing stimulus; $C L$, cycle length.

paroxysmal atrial tachycardia, ventricular extrasystoles, sometimes in the presence of increased sinus rate, and atrioventricular or bundle-branch block were frequently observed in alcoholic patients with no clinically detectable myocardial disease as well as in those with manifest cardiomyopathy (Regan, 1971; Burch and Giles, 1975). Dimpled, bifid, peaked, or narrowly inverted $\mathrm{T}$ waves were thought to be appropriate electrocardiographic ST$T$ changes but in some cases non-specific ST-T changes could also be seen (Evans, 1959; Sereny, 1971; Regan, 1971).

Our patients represent a series of men between the third and fifth decades of life, chronically consuming large quantities of alcohol and with clinically detectable heart muscle disease. In 6 patients in the advanced stage of the disease, chronic atrial fibrillation has been observed; 3 patients with early cardiomyopathy had paroxysmal atrial fibrillation or flutter. In case 1 atrial fibrillation was associ- ated with complete atrioventricular block, and pacemaker implantation was necessary to improve his haemodynamic state. Most of the patients with advanced stage of the disease and chronic atrial fibrillation also had ventricular extrasystoles.

Monophasic action potential recordings together with the determination of the effective refractory periods enhanced an understanding of the underlying electrophysiological mechanism in our patients. The right atrial monophasic action potential duration at 90 per cent and 50 per cent repolarisation and atrial effective refractory period recorded in the mid-right atrium were significantly shorter in alcoholics than in the control group, while no differences could be observed for the right atrial relative repolarisation rate of phase 3 per cent/s in these 2 groups. These changes probably suggest the shortening of phase 1 and 2 of the action potential, while phase 3 remains unchanged (Hoffman et al., 1959), and may account for the frequency of the atrial arrhythmias in these patients (Hoffman and Cranefield, 1964; Cranefield et al., 1973). Monophasic action potential duration in man is shortened under the influence of hyperthyroidism, catecholamines, digitalis, and in patients in whom atrial fibrillation tends to recur after successful conversion (Olsson, 1971; Cotoi et al., 1972a, b). Thyrotoxicosis and digitalis effects were not present in our case but excessive sympathetic stimulation and catecholamine release could not be excluded. Though we have not assessed the tendency to relapse of atrial fibrillation in our patients and have no data on right atrial monophasic action potential duration before chronic atrial arrhythmias developed, it is plausible that there is a correlation between arrhythmias and shortening of right atrial monophasic action potential duration.

In the group of patients in whom atrial fibrillation had been converted to sinus rhythm, the results of multiple recordings of right atrial monophasic action potential and multiple determinations of the atrial effective refractory period showed nonuniformity of the refractoriness as compared to the patients without atrial arrhythmias and the controls. In this group we found the greatest differences between the values obtained at the three sites in the right atrium. The right atrial relative repolarisation rate of phase 3 per cent/s recorded in the mid-right atrium was similar in alcoholics and in controls. However, greater differences could be seen between values obtained at the 3 sites of the right atrium in alcoholics with atrial arrhythmias in comparison with the others. The lack of homogeneity in the rate of repolarisation favours the occurrence of arrhythmias, particularly atrial fibrillation and ventricular extrasystoles (Wit et al., 
Table 2 Main clinical and electrophysiological data obtained in 20 patients with alcoholic cardiomyopathy and mean electrophysiological values obtained in 15 control subjects

\begin{tabular}{|c|c|c|c|c|c|c|c|c|c|}
\hline \multirow{2}{*}{$\begin{array}{l}\text { Case } \\
\text { no. }\end{array}$} & \multirow{2}{*}{ Sex } & \multirow{2}{*}{$\begin{array}{l}\text { Age } \\
(y)\end{array}$} & \multirow{2}{*}{$\begin{array}{l}\text { Cardio- } \\
\text { megaly }\end{array}$} & \multirow{2}{*}{ Surface ECG } & \multirow{2}{*}{$\begin{array}{l}\text { PR interval } \\
(m s)\end{array}$} & \multicolumn{3}{|c|}{ His bundle intervals (ms) } & \multirow{2}{*}{$\begin{array}{l}\text { Paced } \\
\text { Wenckebach } \\
\text { AV block } \\
\text { (rate/min) }\end{array}$} \\
\hline & & & & & & $P A$ & $A H$ & $H V$ & \\
\hline 1 & 2 & 3 & 4 & 5 & 6 & 7 & 8 & 9 & 10 \\
\hline 1 & 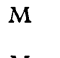 & 49 & $+t+$ & $\begin{array}{l}\text { AF, complete AV block } \\
\text { LBBB, PVB }\end{array}$ & - & - & - & 65 & 一 \\
\hline 2 & M & 45 & $+t$ & AF, LAH, NST, VES & 215 & 20 & 150 & 45 & 118 \\
\hline 3 & $\mathbf{M}$ & 42 & ++ & AF, RBBB, NST & 225 & 20 & 155 & 50 & 125 \\
\hline 4 & $\mathbf{M}$ & 47 & $+t+$ & AF, LBBB, VES & - & 一 & - & 65 & - \\
\hline 5 & $M$ & 40 & ++ & AF, LBBB, VES & 250 & 30 & 150 & 70 & 115 \\
\hline 6 & $\mathbf{M}$ & 24 & ++ & LAH & 190 & 30 & 110 & 50 & 155 \\
\hline 7 & $\mathbf{M}$ & 32 & + & SST & 210 & 35 & 115 & 60 & 130 \\
\hline 8 & $\mathbf{M}$ & 38 & + & SST & 195 & 25 & 125 & 45 & 135 \\
\hline 9 & $M$ & 41 & $+t+$ & LBBB, VES & 220 & 20 & 130 & 70 & 138 \\
\hline 10 & $M$ & 35 & + & SST, VES & 180 & 30 & 100 & 50 & 145 \\
\hline 11 & $M$ & 28 & ++ & LAH, NST,VES & 150 & 40 & 70 & 40 & 160 \\
\hline 12 & $M$ & 39 & ++ & SST, VES & 240 & 35 & 155 & 50 & 120 \\
\hline 13 & $\mathbf{M}$ & 34 & ++ & LPH, PAFl & 190 & 40 & 90 & 60 & 132 \\
\hline 14 & $\mathbf{M}$ & 44 & $+t+$ & LBBB, VES & 210 & 60 & 90 & 60 & 112 \\
\hline 15 & $\mathbf{M}$ & 31 & ++ & AF, NST, VES & 190 & 40 & 90 & 60 & 135 \\
\hline 16 & $\mathbf{M}$ & 30 & + & PAF, SST & 190 & 30 & 110 & 50 & 132 \\
\hline 17 & $M$ & 33 & + & Normal & 175 & 25 & 105 & 50 & 158 \\
\hline 18 & $M$ & 29 & + & PAF & 190 & 30 & 100 & 60 & 130 \\
\hline 19 & $\mathbf{M}$ & 37 & + & SST & 185 & 25 & 120 & 40 & 129 \\
\hline 20 & $\mathbf{M}$ & 39 & + & SST & 170 & 30 & 95 & 45 & 160 \\
\hline \multicolumn{10}{|l|}{ Patients } \\
\hline Mean & & 37 & & & 199 & 31 & 114 & 54 & 135 \\
\hline SD & & 2 & & & 7 & 3 & 17 & 3 & 7 \\
\hline SE & & 2 & & & 6 & 2 & 6 & 2 & 4 \\
\hline No. & & 20 & & & 18 & 18 & 18 & 20 & 18 \\
\hline \multicolumn{10}{|l|}{ Control } \\
\hline Mean & & 37 & & & 157 & 19 & 113 & 44 & 185 \\
\hline SD & & 2 & & & 7 & 3 & 17 & 3 & 7 \\
\hline SE & & 1 & & & 5 & 1 & 16 & 1 & 6 \\
\hline No. & & 15 & & & 15 & 15 & 15 & 15 & 15 \\
\hline \multicolumn{10}{|c|}{ Significance } \\
\hline $5 \%$ & & NS & & & $\mathbf{S}$ & $\mathbf{S}$ & NS & $\mathbf{S}$ & $\mathbf{S}$ \\
\hline
\end{tabular}

,+++ , and +++ , minimal, moderate, and gross; AF, atrial fibrillation; LBBB, left bundle-branch block; LAH, left anterior hemiblock; LPH, extrasystoles; SST, specific ST-T changes; NS, not significant; S, significant. Symbols can be deduced from text.

1974). Possible mechanisms include alterations of cell membrane permeability and stimulation of catecholamine secretion from the adrenal medulla by ethanol (Sereny, 1971).

The right ventricular monophasic action potential duration at 90 per cent repolarisation was longer while the right ventricular monophasic action potential duration at 50 per cent repolarisation, and the ventricular effective refractory period, were shorter in alcoholics than in controls. The right ventricular relative repolarisation rates of phase 3 per cent/s were lower than in controls. Such changes suggest that phase 1 and 2 of the action potential in the right ventricle are shortened while phase 3 is prolonged. The modification in phase 3 of the myocardial action potential could be responsible for the $T$ wave abnormality (Sereny, 1971), but the technique of recording the monophasic action potential does not permit analysis of this phenom- enon. The patients with ventricular arrhythmias showed the greatest differences in the right ventricular monophasic action potential duration at 90 per cent and 50 per cent repolarisation and of the ventricular effective refractory period recorded at multiple sites, though such differences were not found for the right ventricular relative repolarisation rate of phase 3 per cent/s. These local differences in conduction properties and refractoriness in right atrium and ventricle fit the experimental data and may be a factor favouring re-entry (Hoffman and Cranefield, 1960). The changes could be explained by non-uniform histopathological damage of the myocardium and are probably non-specific (Burch and Giles, 1976).

Studies in dogs receiving ethanol, without protein or vitamin deficiencies, have shown significant prolongation of the His-Purkinje conduction time compared with that in controls (Ettinger et al., 


\begin{tabular}{|c|c|c|c|c|c|c|c|c|}
\hline \multicolumn{9}{|c|}{ Paced cycle length (600 ms) } \\
\hline $\begin{array}{l}\text { RAMAP } A P \\
90 \% \\
\text { (ms) }\end{array}$ & $\begin{array}{l}\text { RAMAP } \\
50 \% \\
(\mathrm{~ms})\end{array}$ & $\begin{array}{l}\text { RARRR } \\
\text { phase } 3 \\
\% / s \\
\%\end{array}$ & $\begin{array}{l}R V M A P \\
90^{\circ} \% \\
(\mathrm{~ms})\end{array}$ & $\begin{array}{l}R V M A P \\
50^{\circ} \\
(m s)\end{array}$ & $\begin{array}{l}\text { RVRRR } \\
\text { phase } 3 \\
\%_{0} / s\end{array}$ & $\begin{array}{l}A E R P \\
(m s)\end{array}$ & $\begin{array}{l}\text { AVERP } \\
(m s)\end{array}$ & $\begin{array}{l}V E R P \\
(m s)\end{array}$ \\
\hline 11 & 12 & 13 & 14 & 15 & 16 & 17 & 18 & 19 \\
\hline - & - & - & 340 & 255 & 471 & - & - & 310 \\
\hline 215 & 105 & 364 & 330 & 240 & 444 & 180 & 360 & 300 \\
\hline 210 & 100 & 364 & 335 & 240 & 421 & 185 & 390 & 335 \\
\hline- & - & - & 340 & 260 & 500 & - & - & 320 \\
\hline 215 & 110 & 381 & 350 & 250 & 400 & 180 & 410 & 330 \\
\hline 210 & 105 & 381 & 345 & 265 & 444 & 195 & 335 & 300 \\
\hline 230 & 120 & 364 & 330 & 260 & 571 & 200 & 390 & 315 \\
\hline 205 & 110 & 381 & 340 & 250 & 444 & 190 & 365 & 330 \\
\hline 220 & 120 & 400 & 355 & 220 & 296 & 200 & 415 & 345 \\
\hline 245 & 125 & 333 & 360 & 270 & 444 & 220 & 350 & 320 \\
\hline 230 & 130 & 400 & 335 & 275 & 667 & 205 & 315 & 305 \\
\hline 220 & 115 & 364 & 330 & 240 & 444 & 180 & 385 & 290 \\
\hline 220 & 140 & 500 & 325 & 235 & 444 & 185 & 350 & 285 \\
\hline 230 & 110 & 333 & 340 & 245 & 421 & 200 & 365 & 325 \\
\hline 220 & 115 & 381 & 350 & 260 & 444 & 205 & 350 & 340 \\
\hline 225 & 125 & 400 & 345 & 265 & 500 & 180 & 345 & 310 \\
\hline 240 & 130 & 361 & 330 & 275 & 727 & 210 & 330 & 305 \\
\hline 220 & 135 & 471 & 335 & 285 & 800 & 185 & 350 & 320 \\
\hline 220 & 120 & 400 & 320 & 265 & 727 & 205 & 360 & 285 \\
\hline 230 & 130 & 400 & 310 & 245 & 615 & 215 & 320 & 280 \\
\hline 222 & 119 & 388 & 337 & 255 & 515 & 196 & 360 & 312 \\
\hline 4 & 5 & 15 & 6 & 6 & 35 & 4 & 8 & 5 \\
\hline 2 & 2 & 10 & 3 & 4 & 25 & 3 & 7 & 4 \\
\hline 18 & 18 & 18 & 20 & 20 & 20 & 18 & 18 & 20 \\
\hline 241 & 135 & 387 & 323 & 270 & 753 & 230 & 295 & 324 \\
\hline 4 & 5 & 15 & 6 & 6 & 35 & 4 & 8 & 5 \\
\hline 4 & 5 & 11 & 5 & 5 & 25 & 3 & 4 & 3 \\
\hline 15 & 15 & 15 & 15 & 15 & 15 & 15 & 15 & 15 \\
\hline $\mathbf{S}$ & $\mathbf{S}$ & NS & $\mathbf{S}$ & $\mathbf{S}$ & $\mathrm{S}$ & $\mathrm{S}$ & $\mathrm{S}$ & $\mathbf{S}$ \\
\hline
\end{tabular}

left posterior hemiblock; NST, non specific ST-T changes; PAF, paroxysmal atrial fibrillation; PAFl, paroxysmal atrial flutter; VES, ventricular

1970). Conduction disturbances are common electrocardiographic findings in about one-third of alcoholics and include varying degrees of atrioventricular block and left or right bundle-branch block (Regan, 1971). In cardiomyopathy the conduction defects are believed to be diffuse and the lesions fibrotic (Stapleton et al., 1970). In a series of 70 patients, 90 per cent of whom had alcoholic cardiomyopathy, Bashour et al. (1976) found first degree atrioventricular block in 40 per cent, left bundle-branch block in 6 per cent, left posterior fascicular block in 2 per cent, and 'bifascicular block' in 13 per cent. His bundle electrograms were performed in only a few of these cases. The incidence of the PR prolongation in our patients was 35 per cent, while intraventricular conduction defects were found in 50 per cent. On the surface electrocardiogram 83 per cent of patients with moderate and gross cardiomegaly showed different types of atrioventricular block, while only 25 per cent of patients with minimal cardiomegaly had such conduction disturbances. During electrophysiological studies each alcoholic patient had longer atrioventricular effective refractory periods than the controls, though some patients showed normal atrioventricular nodal conduction times on His bundle electrograms.

Our data show that in alcoholic patients conduction disturbances are frequent and localised at multiple sites in the atrioventricular conduction system. Electrophysiological studies sometimes showed latent conduction disturbances which were not apparent on standard electrocardiographic tracings.

I wish to thank Professor S. Gavrilescu for advice and helpful criticism, and Drs R. Cristodorescu and C. Streian for referring some of their patients. 
Table $3 M A P$ and ERP durations obtained in 3 sites of right atrium and right ventricle and maximum differences (\%) between mean values in same chamber in 8 alcoholic patients and in 4 normal subjects

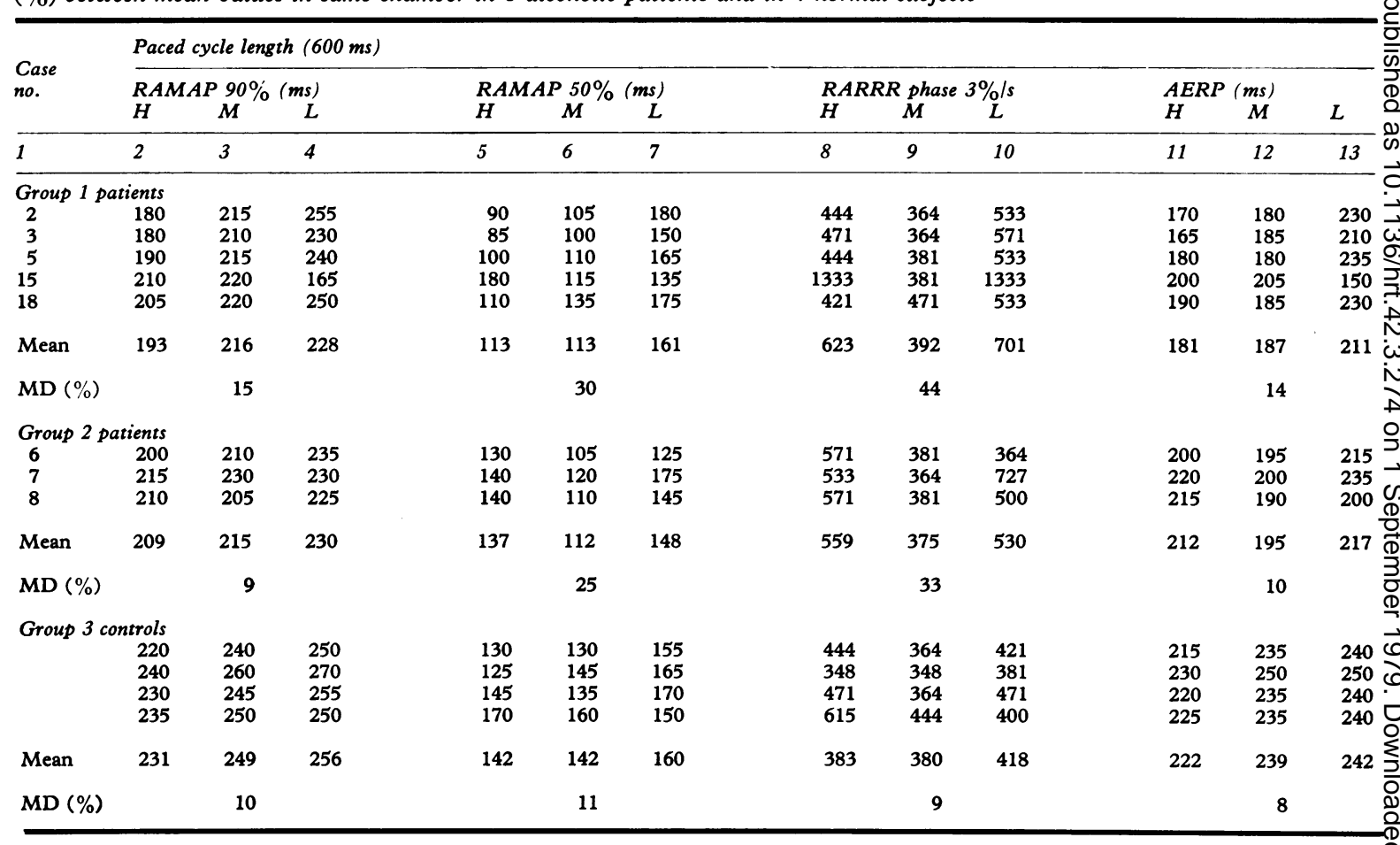

$H, M$, and $L$ are high, middle, and low right atrium; $A, L$, and $B$ are apex, lateral wall, and base of the right ventricle; $M D$ is maximum differences between values obtained in the 3 sites. The other symbols are similar to Table 2 .

\section{References}

Bashour, T. T., Fahdul, H., and Cheng, T. O. (1976). Multifascicular block in cardiomyopathy. Cardiology, 61, 89-97.

Brorson, L. (1975). Electrophysiological Properties of Right Atrium. Gotabkünlav, Göteborg.

Burch, G. E., Colcolough, H. L., Harb, J. M., and Tsui, C. Y. (1971). The effect of ingestion of ethyl alcohol, wine and beer on the myocardium of mice. American fournal of Cardiology, 27, 522-528.

Burch, G. E., and Giles, T. (1976). Cardiomyopathy diagnostic criteria and classification. In Controversy in Cardiology, p. 163, ed E. K. Chung. Springer-Verlag, New York, Heidelberg, and Berlin.

Cabasson, J., Mellet, J. M., Guimond, C., Bachy, C., Sasine, A., and Puech, P. (1975). L'etude des potentiels d'action monophasiques due myocard par voie endocavitaire et ses applications. Annales de Cardiologie et d'Angeiologie, 24, 483-490.

Cotoi, S., Constantinescu, L., and Gavrilescu, S. (1972a). The effect of thyroid state on monophasic action potential in human heart. Experientia, 28, 797-798.

Cotoi, S., Gavrilescu, S., Pop, T., and Vicas, E. (1972b). The prognostic value of right atrium monophasic action potential after conversion of atrial fibrillation. European fournal of Clinical Investigation, 2, 472-474.

Cranefield, P. F., Wit, A. L., and Hoffman, B. F. (1973). Genesis of cardiac arrhythmias. Circulation, 47, 190-204.

Ettinger, P. O., Khan, M. I., Oldewurtel, H. A., and Regan,
T. J. (1970). Left ventricular conduction abnormalities in chronic diabetes and alocholism (abstract). Circulation, 41 and 42, Suppl III, 98.

Evans, W. (1959). The electrocardiogram of alcoholic cardiomyopathy. British Heart fournal, 21, 445-456.

Gavrilescu, S., Cotoi, S., Pop, T., and Luca, C. (1972). The monophasic action potential of the right atrium. In Actas del VI Congreso Europeo de Cardiologia, p. 221. Ed. Pax Montalvo, Madrid.

Gould, L., Reddy, C. V. R., Patel, N., and Gomprecht, R. F. (1974). Effects of a cocktail on the human conduction system (abstract). Clinical Research, 22, 277A.

Hoffman, B. F., and Cranefield, P. F. (1960). Electrophyiology of the Heart. McGraw-Hill, New York.

Hoffman, B. F., and Cranefield, P. F. (1964). The physiological basis of cardiac arrhythmias. American fournal of Medicine, 37, 670-684.

Hoffman, B. F., Cranefield, P. F., Lepeschin, E., Surawicz, B., and Herrlich, H. S. (1959). Comparison of monophasic action potentials recorded by intracellular and suction electrodes. American fournal of Physiology, 196, 1297-1301.

Maines, J. E. III, and Aldinger, E. E. (1967). Myocardial depression accompanying chronic consumption of alcohol. American Heart fournal, 73, 55-63.

Mitchell, J. H., and Cohen, L. S. (1970). Alcohol and the heart. Modern Concepts of Cardiovascular Disease, 39, 109.

Olsson, S. B. (1971). Monophasic Action Potential of Right Heart. Elanders Boktrickery Akienbolog, Göteborg.

Opie, L. H. (1969). Metabolism of the heart in health and 


\begin{tabular}{|c|c|c|c|c|c|c|c|c|c|c|c|}
\hline \multicolumn{3}{|c|}{$R V M A P 90 \%$ (ms) } & \multicolumn{3}{|c|}{$R V M A P 50 \%(m s)$} & \multicolumn{3}{|c|}{ RVRRR phase $3 \% / s$} & \multicolumn{3}{|c|}{$V E R P(m s)$} \\
\hline$A$ & $L$ & $B$ & $A$ & $L$ & $B$ & $A$ & $L$ & $\boldsymbol{B}$ & $A$ & $L$ & $B$ \\
\hline 14 & 15 & 16 & 17 & 18 & 19 & 20 & 21 & 22 & 23 & 24 & 25 \\
\hline $\begin{array}{l}350 \\
360 \\
365 \\
355 \\
330\end{array}$ & $\begin{array}{l}330 \\
335 \\
350 \\
350 \\
335\end{array}$ & $\begin{array}{l}300 \\
330 \\
310 \\
320 \\
310\end{array}$ & $\begin{array}{l}250 \\
270 \\
255 \\
250 \\
260\end{array}$ & $\begin{array}{l}240 \\
240 \\
250 \\
260 \\
285\end{array}$ & $\begin{array}{l}210 \\
250 \\
220 \\
230 \\
250\end{array}$ & $\begin{array}{l}400 \\
444 \\
364 \\
381 \\
444\end{array}$ & $\begin{array}{l}444 \\
421 \\
400 \\
444 \\
800\end{array}$ & $\begin{array}{l}444 \\
500 \\
444 \\
444 \\
667\end{array}$ & $\begin{array}{l}320 \\
350 \\
345 \\
350 \\
315\end{array}$ & $\begin{array}{l}300 \\
335 \\
330 \\
340 \\
320\end{array}$ & $\begin{array}{l}280 \\
310 \\
300 \\
320 \\
300\end{array}$ \\
\hline 352 & $\begin{array}{r}340 \\
10\end{array}$ & 314 & 357 & $\begin{array}{r}255 \\
10\end{array}$ & 232 & 407 & $\begin{array}{r}502 \\
19\end{array}$ & 500 & 336 & $\begin{array}{r}325 \\
10\end{array}$ & 302 \\
\hline $\begin{array}{l}320 \\
330 \\
325\end{array}$ & $\begin{array}{l}345 \\
330 \\
340\end{array}$ & $\begin{array}{l}320 \\
325 \\
320\end{array}$ & $\begin{array}{l}250 \\
260 \\
230\end{array}$ & $\begin{array}{l}265 \\
260 \\
250\end{array}$ & $\begin{array}{l}250 \\
245 \\
250\end{array}$ & $\begin{array}{l}571 \\
571 \\
471\end{array}$ & $\begin{array}{l}444 \\
571 \\
444\end{array}$ & $\begin{array}{l}571 \\
571 \\
571\end{array}$ & $\begin{array}{l}300 \\
305 \\
315\end{array}$ & $\begin{array}{l}300 \\
315 \\
330\end{array}$ & $\begin{array}{l}310 \\
310 \\
320\end{array}$ \\
\hline 325 & $\begin{array}{r}338 \\
5\end{array}$ & 322 & 247 & $\begin{array}{r}258 \\
5\end{array}$ & 248 & 538 & $\begin{array}{r}487 \\
15\end{array}$ & 571 & 307 & $\begin{array}{r}315 \\
3\end{array}$ & 313 \\
\hline $\begin{array}{l}340 \\
355 \\
330 \\
300\end{array}$ & $\begin{array}{l}320 \\
360 \\
315 \\
295\end{array}$ & $\begin{array}{l}330 \\
350 \\
325 \\
300\end{array}$ & $\begin{array}{l}260 \\
290 \\
270 \\
240\end{array}$ & $\begin{array}{l}260 \\
305 \\
265 \\
245\end{array}$ & $\begin{array}{l}240 \\
280 \\
260 \\
250\end{array}$ & $\begin{array}{l}500 \\
615 \\
500 \\
666\end{array}$ & $\begin{array}{l}667 \\
727 \\
800 \\
800\end{array}$ & $\begin{array}{l}444 \\
571 \\
615 \\
800\end{array}$ & $\begin{array}{l}330 \\
350 \\
320 \\
290\end{array}$ & $\begin{array}{l}340 \\
345 \\
325 \\
305\end{array}$ & $\begin{array}{l}315 \\
340 \\
210 \\
300\end{array}$ \\
\hline 331 & $\begin{array}{r}322 \\
3\end{array}$ & 326 & 265 & $\begin{array}{r}268 \\
4\end{array}$ & 257 & 571 & $\begin{array}{r}748 \\
24\end{array}$ & 608 & 323 & $\begin{array}{r}329 \\
4\end{array}$ & 316 \\
\hline
\end{tabular}

disease. Part III. American Heart fournal, 77, 383-410.

Puech, P., Cabasson, J., Latour, H., Grolleau, R., Baissus, C., and Mellet, J. M. (1974). Etude des potentiels d'action monophasiques due myocarde par voie endocavitaire. Archives des Maladies du Coeur et des Vaisseaux, 67, 1117-1122.

Regan, T. J. (1971). Ethyl alcohol and the heart. Circulation, 44, 957-963.

Scherlag, B. J., Lau, S. H., Helfant, R. H., Berkowitz, W. D., Stein, E., and Damato, A. N. (1969). Catheter technique for recording His bundle activity in man. Circulation, 39, 13-18.

Sereny, G. (1971). Effects of alcohol on the electrocardiogram. Circulation 44, 558-564.

Stapleton, J. F., Segal, J. P., and Harvey, W. P. (1970). The electrocardiogram of myocardopathy. Progress in Cardiovascular Diseases, 13, 217-239.
Trautwein, W. (1970). Mechanisms of tachyarrhythmias and extrasystole. In Symposium on Cardiac Arrhythmias, Elsinore, Denmark, p. 53. Astra.

Wit, A. L., Rosen, M. R., and Hoffman, B. F. (1974). Electrophysiology and pharmacology of cardiac arrhythmias. II Relationship of normal and abnormal electrical activity of cardiac fibers to the genesis of arrhythmias B. Re-entry. Section I. American Heart fournal, 88, 664-670.

Wit, A. L., Weiss, M. B., Berkowitz, W. D., Rosen, K. M., Steiner, C., and Damato, A. N. (1970). Patterns of atrioventricular conduction in the human heart. Circulation, Research, 27, 345-359.

Requests for reprints to Dr C. Luca, Bul. St. Plavat, Nr. 141, Ap. 44, 1900 Timisoara, Romania. 